\title{
NOTAS CRÍTICAS A DOS HIMNOS LITÚRGICOS MOZÁRABES ${ }^{1}$
}

The author establishes the texts of the Mozarabic Hymns to St. Bartolomé and to the Sts. Facundo and Primitivo, previously edited, with a large number of corrections, by Blume in Analecta Hymnica Medii Aeui XXVII. In both hymns he tries to follow and always maintain the original text of the corresponding manuscript as far as possible, and succeeds in making them more intelligible.

\section{Himno a san Bartolomé.}

El establecimiento del texto del himno en honor de san Bartolomé presenta grandes dificultades, resultando ininteligible en numerosas ocasiones. El himno se ha conservado solamente en el ms. del Museo Británico Add. 30851. Por otra parte no contamos con la pasión en prosa del santo, único medio de poder comprender el texto.

Son cuarenta y cuatro las correcciones propuestas por Blume a un himno de cincuenta versos, número que puede resultar excesivo, sobre todo si se tiene en cuenta el buen estado del ms. Un buen número de estas correcciones no sólo no mejora el texto, sino que, nos atreveríamos a decir, lo empeora. Pasando por alto aquellos casos, numerosos, en que es posible mantener el texto del ms., voy a centrarme en los textos que resultan de más dificil comprensión.

' El presente estudio está hecho sobre el texto de la obra de C. Blume y G. M. Dreves, Mozarabischen Hymnen (Analecta Hymnica Medii Aeui, XXVII), Leipzig 1879. La lectura que proponemos como correcta mantiene la grafia del ms., siguiendo el criterio que Juan Gil propone en su artículo «Para la edición de los textos visigodos y mozárabes», Habis 5, 1973, pp. 189-234. Mi agradecimiento a los profesores Gil y Correa por su valiosísima ayuda. 
97,1 Exaudi, Christe, nos patris potens, pie, celse, te semper obsecramus, inclite, celsus qui solus es Deique filius, es qui dilectus, ecce, matris unicus, ymnum perfectum et canorum dicimus.

Celso de, lección del ms. (v. 2), es corregido por Blume en celse, te, restándole, en nuestra opinión, comprensión al texto. La anástrofe, no tan fuerte como en otros casos del Himnario, se explicaría, según Bannister, por el acróstico ${ }^{2}$. En el verso siguiente vuelve a aparecer celso, también al comienzo. Aunque hay razones para explicar la corrección de Blume, celsus, también las hay para mantener celso del ms., que, en nuestra opinión, podría oponerse a ecce del verso siguiente, paralelo en forma y contenido al verso que estudiamos. Tampoco veo razones para corregir caterba del ms. en canorum, como hace Blume. Debe modificarse la puntuación, quedando el texto como sigue:

97,1 Exaudi, Xriste, nos, patris potens, pie, celso de. Semper obsecramus, inclite, celso qui solus es deique filius, es qui dilectus ecce matris unicus; ymnum perfectum et caterba dicimus.

97,2 Multis cum saepe dulcibusque uocibus nec non nunc ergo mitigando consonis uerbis et corde personemus inclitum seruis cum irae Spaniae fidelibus bis laudet chorus ergo recte filium.

El ms. da para el conflictivo verso 2 mitigando consimus. Frente a la tentadora corrección de Blume, consonis, creo que podría mantenerse la lectura del ms., a pesar de las serias dificultades que esta forma pueda plantear, desde el punto de vista léxico y métrico. En efecto, sólo encontramos documentadas formas del perfecto confuit, y solamente en una ocasión con el valor puramente etimológico de simul esse, que pretendemos ver en el presente texto ${ }^{3}$. Desde el punto de vista métrico, consimus, presente de subjuntivo, no sería posible, como palabra llana, en final de trímetro yámbico. Podría entonces tratarse de con-símus, presente de indicativo, en lugar de con-sŭmus.

Simus, presente de indicativo, se explicaría por influjo dialectal itáli-

2 J. P. Gilson, The mozarabic psalter, Londres 1905, p. 237.

${ }^{3}$ ThLL IV confuit, col. 259. 
co, según el profesor Tovar ${ }^{4}$. Esta forma, en lugar de sumus, está documentada en latín antiguo ${ }^{5}$. De aquí, según el mismo profesor Tovar, se origina el español semos, "arcaísmo rústico muy extendido en la Península», siendo esto una prueba de la presencia de elementos itálicos en el latín de Hispania. Hay que añadir que el himno a san Bartolomé es posterior a la invasión sarracena. En estos himnos, según Pérez de Urbel, «la lengua se acerca más al modo de hablar del pueblo» ${ }^{6}$. Para el ininteligible verso 4 conjeturo mire. Sería fácil explicar la supresión de la $m$ - inicial, tras la $-m$ final de la palabra anterior, por un simple salto de ojos. El texto quedaría como sigue:

97,2 Multis cum sepe dulcibusque uocibus; necnon nunc ergo mitigando consimus. uerbis et corde personemus inclitum seruis cum mire Spanie fidelibus, bis laudet chorus ergo recte filium.

97,7 Ergo qui infirmos aduenit poposcere maestos uinctosue ipse tunc uel sospites fulgens sanabat, immo sanctus optime et collocabat insuper perenniter cum sanctis rite Bartholomaeus hic bene.

Infirmus, del ms., referido a Bartolomé, podría enfatizar el sanabat del verso 3. Por ello mantenemos esta lectura frente a la corrección de Blume en infirmos. El difícil verso 2 del ms. mestis uinclis uel ipse tunc uel spite, ininteligible, es corregido por Blume, no con demasiada fortuna, ya que sigue resultando ininteligible. La corrección maestos que Blume propone para mestis del ms. mejora, en mi opinión, el texto. No ocurre igual, sin embargo, con uinctosue, conjetura para uinclis uel del ms. y sospites para spite del ms. Preferimos mantener uinclis uel del ms. y conjeturamos stipite para el final del verso, que se opondría al ipse anterior. En el verso 4 no hay ninguna necesidad de corregir, como hace Blume, conlocabit del ms., entendido como perfecto. Proponemos, pues, el siguiente texto:

4 A. Tovar, "Ascendencia del español vulgar semos», Corollas Philologicas in honorem Iosephi Guillén Cabañero. Publicaciones de la Universidad Pontificia de Salamanca, 1983, pp. 613-618.

s Suet. Aug. 87, 1 s.; Mar.-Vict., GLK VI 9, 5; CIL IX 3473.

- J. Pérez de Urbel, "Origen de los himnos mozárabes", Bulletin Hispanique 28, 1928, pp. 5-21, 113-139, 209-245, 305-320. 
97,7 Ergo qui infirmus aduenit poposcere mestos uinclis uel ipse tunc uel stipite fulgens sanabat ymmo sanctus obtime et conlocabit insuper perenniter cum sanctis rite Bartolomeus hic bene.

97,9 Mercatus magne sancte seu apostole, exaudi nostra saepia praeconia, linquens peccata nostra uel facinora furuum serpentem et inuidum, comissime iudex, subuerte, tergatur ter sulfure.

Gilson propone la corrección mercator para el dificil mercatur del ms. ${ }^{7}$. Creo corrección más acertada ésta que la propuesta por Blume mercatus. Innecesaria es también la corrección de Blume linquens al liquens del ms. Son dificiles de entender los dos últimos versos. En el ms. se lee furuam serpentem et inuidam tonissimam iudex subuerte tergate ter sulfura. Si bien no he podido encontrar apoyo para mantener la lección del ms. tonissimam, tampoco encuentro explicación para la corrección que en este caso propone Blume, comissime. He pensado en algún momento en uanissimam, pero esta conjetura no tendría más fundamento que la de Blume. Por todo ello preferimos mantener la lección del ms. No parece necesario, por otra parte, alterar el género de furuam... inuidam, ya que, como sabemos, serpens puede usarse con los dos géneros. En el último verso no aclara nada la corrección de Blume tergatur ter sulfure, ni la que tímidamente apunta Gilson ${ }^{8}$, terge et sulfura. Propongo leer et terga ter sulfura, entendiendo este último verbo como imperativo de un inusitado sulfuro, con el significado de 'llenar de azufre' 9 . El texto quedaria asi:

97,9 Mercator magne sancte seu apostole, exaudi nostra sepia preconia; liquens peccata nostra uel facinora, furuam serpentem et inuidam tonissimam iudex, subuerte, et terga ter sulfura.

En 10,3 el ms. da et nunc et per secla seclorum in omnia, corregido por Blume en nunc et per saecla saeculorum in omnia. No creo necesario

7 J. P. Gilson, op. cit., p. 238.

8 J. P. Gilson, op. cit., p. 238.

- A. Forcellini, Lexicon totius latinitatis, Padua 1965, sulfuratus, p. 585. 
suprimir et del comienzo ni conjeturar saeculorum en lugar de seclorum del ms. Creo que el verso mejora suprimiendo únicamente la preposición in, evidentemente introducida después de per por un cruce entre in omnia secla y per omnia secla.

\section{Himno a los santos Facundo y Primitivo.}

Este himno también se ha conservado en un solo ms., el MC, número 30 de la Biblioteca de la Real Academia de la Historia de Madrid. Se ha conservado en cambio la pasión en prosa de estos santos.

120,2 Cunctumque rabidi per hoc satellites orbem disquiritant, Christum colentium auidis faucibus luporum ritibus sanguinem sitiunt, insontes perimunt.

Euumque rauidum del ms., leído por Blume eumque rabidi, es corregido por él en cunctumque rabidi, dificultando la comprensión del texto. Creo encontrar en la pasión apoyo para mantener la lección del ms. Alli se lee: 2 In temporibus illis, dum omnem uniuersum demens sacrilegus imperatorum furor concuteret, et omnes christianos ad sacrilegum demonum cultorem crebra impulsio coartaretur ${ }^{10}$. Para el verso 3 propone el profesor Gil rictibus en lugar de ritibus del ms., que, según él, no casa bien con faucibus ". Se me ocurre pensar si no sería posible mantener la lección del ms. ritibus, con el valor del singular ritu 'a modo de', cosa que ocurre con el empleo figurado de algunas palabras, como en el caso de manu / manibus 'fuerza'. Desgraciadamente ésta no pasa de ser una mera especulación, ya que no he podido documentar este empleo. La estrofa queda del modo siguiente:

120,2 Euumque rauidum per hoc satellites orbem disquiritant, Xristum colentium auidis faucibus luporum rictibus sanguinem sitiunt, insontes perimunt.

120,3 Monitis obnuunt, quae Christus indidit et suis imperant nefanda incolis.

${ }^{10}$ A. Fábrega Grau, Pasionario Hispánico, Madrid 1965, II, p. 47.

"J. Gil, «El himnario gótico", Habis 7, 1976, p. 203. 
Nefandis incoli del ms. podría aclarar el sentido de este verso, acercándolo a la pasión, donde se lee: 2... Quumque ingressus fuisset quamdam urbem, et omnem regionem suis ordinationibus subiugasset, iussit preconiam intonare uocem ut omnes, statuto die, in unum conuenirent ad sacrificandum ${ }^{12}$.

120,4 Praecones ualida munera largitant, quiesset deditus idolis seruulus, abundans copia, saeculi gloria et manens in eo omni liminio.

No hay motivo alguno, como dice el profesor Gil, para alterar quis en $q u i^{13}$. Tampoco lo vemos para corregir preconans del ms. en praecones. Para el dificil último verso, que Blume lee in ero y para el que propone la corrección in eo, el profesor Gil propone in euo. En el ms. puede leerse, aunque con cierta dificultad, et manens libero omni liminio. Creemos preferible entender por liminio 'exilio, destierro, cautividad', en lugar de 'derecho a la propiedad', como apunta el profesor Gil ${ }^{14}$. Por otra parte creo que debe corregirse el inexplicable libero del ms. en liber. Al mismo tiempo conjeturo $a b$, que regularizaría la sintaxis y el número de sílabas del verso. Es escaso el apoyo que para estas conjeturas encontramos en la pasión, en la que se lee: $2 \ldots$ Talem etiam dederat edictum, ut quicumque sacrificasset, magnis honoribus ditaretur; qui uero christianus inuentus fuisset aut sacrificare contemnisset, diuerso penarum genere puniretur. Propongo pues para este verso la siguiente lectura: et manens liber ab omni liminio.

José Castro SÁnchez

12 A. Fábrega Grau, op. cit., p. 47.

13 J. Gil, op. cit., pp. 203-204.

14 J. Gil, op. cit., pp. 203-204; Du Cange, Glosarium mediae et infimae latinitatis, Graz 1954, IV-V liminium, p. 113; J. F. Niemeyer, Mediae latinitatis lexicon minus, Leiden 1976, liminium, p. 613. 